\title{
Tethered Cord Syndrome in a Child with Beta Thalassemia
}

\author{
Ngo Minh Xuan* \\ Pham Ngoc Thach University of Medicine, Ho Chi Minh city, Vietnam
}

*Corresponding author: Ngo Minh Xuan, Pham Ngoc Thach Medical University, 2 Duong Quang Trung Street, District 10,

Ho Chi Minh City, Vietnam

\begin{abstract}
ARTICLE INFO
Received: March 28, 2020

Published: 慧 April 06, 2020

Citation: Ngo Minh Xuan. Tethered Cord Syndrome in a Child with Beta Thalassemia. Biomed J Sci \& Tech Res 26(5)-2020. BJSTR. MS.ID.004423.

Abbreviations: POD: Postovulatory Day; CCM: Caudal Cell Mass; OSD: Occult Spinal

\section{ABSTRACT}

Tethered cord syndrome is a stretch-induced functional disorder associated with the fixation (tethering) effect of inelastic tissue on the caudal spinal cord, limiting its movement. This abnormal attachment is associated with progressive stretching and increased tension of the spinal cord as a child ages, potentially resulting in a variety of neurological and other symptoms. Due to the variation of the growth rate of the spinal cord and the spinal column, the progression of neurological signs and symptoms is highly variable. We report a very rare case of pediatric patient of tethered cord syndrone with a known history of beta thalassemiaand presented with incontinence of urine and stool since birth and progressive weakness of both lower limbs. Other associated features and radiological findings are also discussed.
\end{abstract} Dysraphism; UDS: Urodynamic Studies
Keywords: Tethered cord syndrome, Occult spinal dysraphism, Low conus medullaris, Myelomeningocele, Thalassemia

\section{Introduction}

A tethered spinal cord is best defined as an abnormal attachment of the spinal cord to the tissues that surround it. The term has acquired a number of different meanings over time. This label has been applied to descriptions of radiographic findings and to varied constellations of clinical signs and symptoms. For example, in 1976 Hoffman and colleagues [1] used the phrase "tethered spinal cord" to define a radiographic diagnosis-a spinal cord "with a low conus medullaris and a thickened filum terminale measuring $2 \mathrm{~mm}$ or more in diameter," excluding other conditions such as "lipomyelomeningoceles, meningoceles, myelomeningoceles, diastematomyelia, and intraspinal space-occupying dysraphic conditions such as dermoid tumors, intraspinal meningoceles, neurenteric cysts, and teratomatous cysts"'[1] Many of which today are considered typically representative of tethering of the spinal cord. TCS is an entity described as an array of congenital anomalies, including cutaneous, urologic, neurologic, and orthopedic systems. It is thought to result from the abnormal fixation of the distal spinal cord secondary toa developmentally acquired or post-operative pathology. Unlike spina bifidaaperta (i.e., myelomeningocele), which is readily diagnosed prenatally, spina bifidaoccultaoften manifests more insidiously. As a result, these closed defects are usually discovered following symptom onset or incidentally during an unrelated work up of coincident comorbidities. Because the prognosis of this syndrome is highly dependent on symptom duration, it is important that all disciplines potentially involved (urology, orthopedics, dermatology, pediatricians, etc.) be aware of this condition as delay in diagnosis can have serious longterm effects.

\section{Case Report}

A6 year old male patient presented to us with complaint of incontinence of urine and stool since birth and weakness of both lower limbs since he was2 years old. Incontinence of urine and stool was first noticed by his parents when he didn't achieve control over urine and stool at the age when a normal child should have achieved. Weakness of both lower limbs was noticed by patient himself from last 6 months, which was intermittent \& worsened after activities involving bending of spine. There was no history 
of seizures, headache \& intellectual deterioration. Vital signs were normal. His general physical examination revealed a small $2 \times 2 \mathrm{~cm}$ sized dimple over sacral region which had a tuft of hairs overlying it, foot deformity in the form of pes cavus and varus, single testis (right) since birth . Central nervous system examination revealed diminished motor power (3/5) into both lower limbs, Deep tendon reflex: knee/Ankle reflexes were diminished, Babinski sign was negative. Sensory system examination was normal. Other systemic examination was normal. Magnetic Resonance Imaging-Brain and spine revealed mild dilatation of bilateral lateral ventricles with normal third and fourth ventricles, $\mathrm{T} 2 \mathrm{~W}$ sagittal sequence reveals non-visualization of coccyx vertebrae and linear hypo-intense tract extending from skin to coccyx region. The lower end of the cord is reaching upto L3-L4 level (Figure 1).

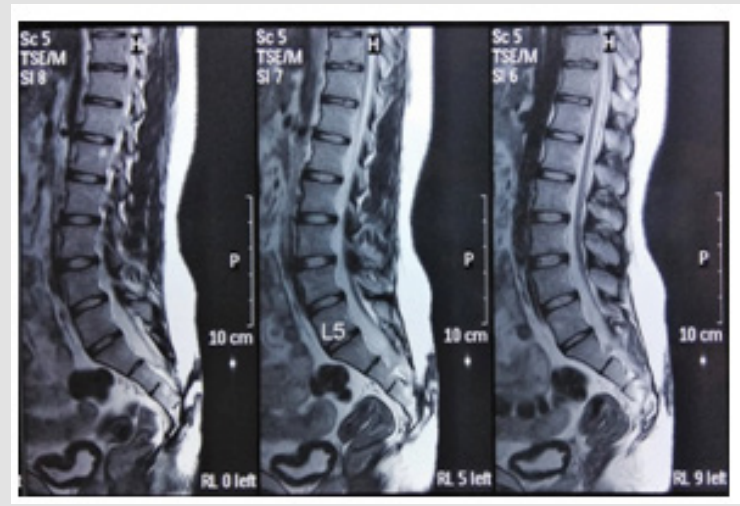

Figure 1: MRI-Spine-T2W sagittal sequence reveals nonvisualisation of coccyx vertebrae and linear hypointense tract extending from skin to coccyx region with lower end of cord is reaching upto L3-L4 level.

Magnetic Resonance Imaging-Abdomen and pelvis revealed small contracted Left sided undescended testis with thickened trabeculated wall of urinary bladder, possibly neurogenic bladder. The left testis is seen at the deep left inguinal canal and appears small in size, it measures approx $10 \mathrm{~mm} \times 14 \mathrm{~mm}$. Review of his available record from the first surgery revealed homozygous beta thalassemia major diagnosed since he was 3 years old, treated with regular blood transfusions and iron chelationHis laboratory work showed the following to be outside of normal limits; Hb\% $8.5 \mathrm{~g} \%$, platelets $130,000 / \mathrm{mm}^{3}$, total bilirubin raised to $2.0 \mathrm{mg} / \mathrm{dl}$ (normal value up to $1.0 \mathrm{mg} / \mathrm{dl}$ ), and alanine aminotransferase raised to59 IU/L (normal up to $40 \mathrm{IU} / \mathrm{L}$ ). An ultrasound of the abdomen done, at the time, showed moderately enlarged liver and spleen with no focal lesions, discounting the presence of EMH in these organs.

\section{Discussion}

\section{History}

As early as the mid-19th century, there were descriptions of spinal cord tethering and related symptomatology. Johnson, in 1857, discusses a fatty sacral tumor connected with spinal membranes in a child. In 1891, in England, Jones performed the first successful intervention for tethered cord. In 1910, Fuchs observed incontinence with spinal flexion in myelomeningocele patients that was attributed to increased tension on the distal spinal cord $[2,3]$. While several other contemporaries discussed observations consistent with tethered cord, it wasn't until 1976 that the term "tethered spinal cord" finally emerged as a designation; Hoffman et al. coined the phrase to describe a series of 31 surgical patients with an abnormally low lying conus medullaris and thickened filum ( $>2 \mathrm{~mm}$ ) whose symptoms improved following sectioning of the filum [1]. Severalauthors have attempted to determine what constitutes a "normal" conus level. Their findings vary from the $\mathrm{T} 12$ to the inferior aspect of $\mathrm{L} 2$, with the most common termination at or above L1/L2 [4-8]. For the remainder of this paper, normal conus will be considered one that terminates at or above the L2 vertebral body.

\section{Embryology}

The spinal cord forms as the result of two distinct processes: primary and secondary neurulation. Primary neurulation entails the proliferation and folding of neuroectoderm intoa neural tube that ultimately comprises the spinal cord. This process begins on postovulatory day (POD) 18; the notochord induces the overlying ectoderm to proliferate as neuroectoderm, forming a groove that progressively elevates until it fuses and forms the neural tube. Cutaneous ectoderm (which eventually becomes skin) separates from the neuroectoderm and fuses on the midline during a critical process called "disjunction." The mesoderm forms the posterior bony and soft tissue elements. Disruption of this stage is responsible for many spinal cord pathologies, including, myelomeningocele (nondisjunction), lipomyelomeningocele (premature disjunction), and dermal sinus tract (incomplete disjunction). Closure of the neural tube begins around POD 22 at the site of future cervical levels; it precedes both rostrally and caudally. Closure of the rostral and 
caudal neuropore occurs by POD 26 and POD 28, respectively. The formation of the brain and the spinal cord mark the end of primary neurulation. Developmental failure of the primary neurulation process may result in an open neural tube defect. Secondary neurulation refers to the formation of distal spinal elements caudal to $\mathrm{S} 2$ as well as the filum. This phase of development occurs between POD 28 and 48. Neuroectoderm caudal to the posterior neuropore, also known as the "caudal cell mass (CCM)," begins canalization.

During this process, the vacuoles that form in the middle of the CCM coalesce with the vacuoles located in the neural tube's central canal [9]. Subsequently, disproportionate growth rates between the spinal cord and the vertebral column cause the spinal cord toascend and pull away from its sacral attachments. The cauda equine forms as nerve roots elongate toaccommodate the differential growth. This process of retrogressive differentiation continues until the conus reach the adult level by three months of age. Errors that occur during canalization or regression are thought to contribute to the formation of low lying conus, terminal lipomas/myelocystoceles and fatty filum pathology [9-11].

\section{Pathophysiology}

Our understanding of TCS pathophysiology has primarily been built upon the work conducted by Yamada et al. over the last 30 years. The authors postulated that progressive low to moderate traction placed on the filum causes a reduction of cytochrome $\mathrm{a}, \mathrm{a}^{3}$, which indicates an ischemic state. Using animal models, Yamada's group showed that the degree of caudal traction on the spinal cord correlated with the severity of neurological deficit secondary to the impairment of oxidative metabolism [12]. They also demonstrated a proportional reduction in spinal cord blood flow in relation to the force of traction, which they designated as "traction induced hypoxia" [12]. Their model also showed how chronic tension can preload the cord in such a way that even minor additional traction can cause severe, permanent damage [13]. A study conducted by Stetler et al. showed that the tethering of the filum terminale caused a reduction in the blood flow to the spinal cord, leading to tissue hypoxiaas a result of mitochondrial redox dysfunction [14]. Metabolic derangements were corrected following restoration of blood flow; however, if blood flow was interrupted for longer periods of time, recovery was only partial. Under these circumstances, it appears that excessive tension can cause irreversible changes and permanent dysfunction that will not be restored following tethered cord release.

\section{Clinical Presentation}

Common presenting signs and symptoms include cutaneous signatures associated with occult spinal dysraphism (OSD) (59\%); neurogenic bladder (18\%), lower extremity weakness, numbness, or spasticity (12\%), leg or foot discrepancy (6\%), foot deformity, spinal deformity, and non-dermatomal leg/back pain (6\%) [15]. While children often present with a combination of findings, symptoms can also be isolated toone system. This diverse presentation is one of the reasons why it is so crucial for physicians toacquaint themselves with the clinical picture of TCS. The diagnosis of various syndromes should also encourage physicians to evaluate patients for OSD, as the twoare often associated with each other. Significant cutaneous lesions can be seen in up to $3 \%$ of the general population; in patients with OSD, the incidence approaches $80 \%$ and there is a greater chance that multiple lesions will be detected upon careful examination [11,16,17]. At times, these findings may be the only symptoms indicating underlying dysraphism. Cutaneous discrepancies include midline hairy patches, hemangiomas, dermal pits/sinuses, hypertrichosis, subcutaneous lipoma, "cigarette burns," lumbosacral appendage, and nevi. While the appearance of any of the aforementioned findings is sufficient to warrant investigation, recent work spanning 12 years of pediatric pa tients suggests that an isolated sacral dimple in an otherwise asymptomatic child has a significantly low association with tethered cord syndrome; the incidence of necessary surgical de-tethering in that population ranged from only 0.13 to $0.17 \%$ [18-20].

That being said, ultrasound is simpler to perform and easier toobtain than an Magnetic Resonance Imaging at a later point when the child may already have become symptomatic and will also require sedation. Urologic dysfunction is most commonly the initial derangement in OSD-related tethering. Patients encounter problems that range from blatant incontinence to subtle changes observed during urodynamic studies. Presentation may include incontinence, urinary urgency, increased urinary frequency, and recurrent UTIs; in the pediatric population, these symptoms tend to be more subtle than other clinical findings [14]. Because bladder dysfunction is difficult toassess in infants, these problems may not even become apparent until children are much older. The most common bladder symptom among toddlers is delayed or unsuccessful toilet training; during testing, detrusor hyperreflexia is the most common finding. Because a disruption in urodynamics often precedes clinical symptoms, this highlights the importance of urological work toaid in preventing delayed diagnosis and treatment. Besides detrusor hyperreflexia, other common symptoms include diminished bladder compliance, external detrusor sphincter dyssynergia, decreased sensation, and hypocontractile destrusor function [21,22].

Neurological problems that manifest in TCS involve the disruption of the motor and sensory pathways of the lower extremities. Although they comprise elements of upper and lower motor neuron dysfunction, motor deficits are more prevalent than sensory deficits [14]. Sensory deficits, if present, are in the feet or perineum or children may present with painless ulcerations of the feet/legs. Orthopedic abnormalities are found in more than $90 \%$ of patients with TCS [14]. Among children, foot deformities are most common. These deformities most likely result from neuromuscular 
imbalance at a time when bones are growing and aligning; deformities are unlikely toarise later in life if mal-alignment does not occur during this period. Other abnormalities include limb length discrepancies, gluteal asymmetry, vertebral anomalies, and scoliosis. Progressive scoliosis or kyphosis can be seen in about $25 \%$ of children with TCS and may also contribute to complaints regarding pain. Vertebral anomalies are commonly observed in children with TCS. These include bifid vertebrae, laminar anomalies, hemivertebrae and sacral agenesis. Segmentation errors may be multiple and these boney abnormalities can be observed in approximately $95 \%$ of children with TCS [11]

\section{Diagnosis}

Table 1: Common presentation of tethered cord syndrome [25]

\begin{tabular}{|c|c|}
\hline System & Characteristics \\
\hline Cutaneous & $\begin{array}{c}\text { Hemangiomas, Dermal pits/sinuses, Hypertrichosis, } \\
\text { Subcutaneous lipoma, "Cigarette burns", Lumbosacral } \\
\text { appendage(s), Nevi }\end{array}$ \\
\hline Neurologic & $\begin{array}{c}\text { UMN signs: hyperreflexia, spasticity } \\
\text { LMN signs: hyporeflexia, muscular atrophy } \\
\text { Mixed upper and lower motor neuron signs } \\
\text { Feet/perineal sensory loss } \\
\text { Back/leg pain }\end{array}$ \\
\hline Urologic & $\begin{array}{c}\text { Gait difficulty/Delayed ambulation } \\
\text { Detrusor hyperreflexia, Frequent urinary tract } \\
\text { infections, Incontinence, Delayed toilet training }\end{array}$ \\
\hline Orthopedic & $\begin{array}{c}\text { Foot deformities, Gluteal asymmetry, Vertebral } \\
\text { anomalies, Scoliosis }\end{array}$ \\
\hline Vertebral & $\begin{array}{c}\text { Bifid vertebrae, Sacral agenesis, Sacral aplasia, } \\
\text { Laminar defects, Hemivertebrae }\end{array}$ \\
\hline
\end{tabular}

Diagnosis of TCS requires the correlation of clinical symptoms with relevant radiographic findings. Presently, toour knowledge, there has never been a case of TCS that was reported with normal imaging. Among the various radiographic procedures available, plain X-rays have the most limited application; they are primarily used to follow the progression of scoliosis. Ultrasound is ideal for infants because there is no need for radiation or sedation. It is also reported to have $96 \%$ sensitivity and $96 \%$ specificity [18]. That being said, ultrasound is limited by operator abilities and often difficult to interpret. Additionally, its use is restricted to infants 4-6 months old because spine ossification reduces the reliability of ultrasound findings $[18,23]$. It can, however, function as a screening tool. If ultrasound results are normal in the setting of sacral dimples or isolated strawberry hemangioma, then the probability of TCS is relatively low and Magnetic Resonance Imaging studies can be postponed [24,25]. Magnetic Resonance Imaging is the imaging procedure of choice for the assessment of OSD/TCS. T1weighted imaging provides clear anatomical detail of neural tissue and the filum. This enables visualization of vertebral levels, the conus position, and the presence of fat/thickening/syrinx. Sagittal views allow for level localization while axial views display fat and the diameter of the filum. As mentioned before, a filum below the L2 vertebral body or thicker than $2 \mathrm{~mm}$ is considered abnormal in children. The absence of movement between supine and prone MR imaging would also indicate a diagnosis of TCS [1]. MR imaging can also reveal urologic sequelae, such as a distended bladder (Table 1).

T2-weighted imaging permits the identification of spinal cord tumors and fluid containing structures. Complete imaging of the entire neuroaxis is important for the screening of "skip lesions" or other abnormalities that are often observed in association with TCS (i.e., Myelomeningocele, Split cord malformation, dermal and lipomatous tumors, etc.) Using only medical history and examination to determine the cause of bladder dysfunction in children can be problematic without the assistance of urodynamic studies (UDS). Because TCS symptom reversal is associated with the duration of dysfunction, patients will have a better chance for successful outcomes if urodynamic studies are implemented early to help establish a definitive diagnosis. UDS can also indicate clinical deterioration and provide a way for physicians to monitor patient improvement following a detethering procedure. For these reasons, physicians should obtain UDS prior toand following any surgical procedure. The most common UDS finding is detrusor hyperreflexia. The following metrics may also be identified: decreased bladder compliance, dyssynergia, and decreased sensation. Important aspects of bladder function assessment include: bladder capacity, bladder pressure, leak point pressure, compliance, uninhibited contractions, EMG activity, and sensation [10].

\section{Conclusion}

The prompt identification of TCS still represents a major clinical challenge. Some of the obstacles contributing to that challenge are symptom ambiguity, presentation discrepancy, and the absence of a standardized pathology accounting for the majority of OSD cases resulting in pediatric TCS. These factors are particularly problematic with respect to timely diagnosis and treatment of children. Because the duration of tethering is a key determinant in disability and recovery, it is paramount that physicians from various specialties establish a uniform understanding of the physiology, presentation, classification, and treatment of OSD. Additionally, given that presentation of OSD can be limited to subtle changes in urodynamic studies, it is imperative that a dedicated multidisciplinary team of specialists (including pediatric urologists, pediatric neurosurgeons, pediatric orthopedic surgeons, and physiatrists) evaluate patients with suspected TCS. While the true incidence of OSD is unknown, advanced imaging, a greater clinical awareness, and ongoing relevant publications assist in making this condition a more mainstream diagnosis among primary care physicians.x’.

\section{References}

1. Hoffman HJ, Hendrick EB, Humphreys RP (1976) The tethered spinal cord: Its protean manifestations, diagnosis and surgical correction. 
Childs Brain 2(3): 145-155.

2. Hertzler DA, De Powell JJ, Stevenson CB, Mangano FT (2010) Tethered cord syndrome: A review of the literature from embryology toadult presentation. Neurosurg Focus 29: e1.

3. Fuchs A (1910) Euber beziehungen der enuresis nocturna zu rdimentarformen der spina bifidaocculta (myelodisplasie). Wien Med Wochenschr 80: 1569-1573.

4. Mc Lone D, Warf B (2001) Pathophysiology of tethered cord syndrome Pediatric Neurosurgery: Surgery of the Developing Nervous system $4^{\text {th }}$ Edn.). 20: 282-288.

5. Drake J (2007) Surgical management of tethered spinal cordwalking the fine line. Neurosurg Focus 23: E8.

6. Pang D, Wilberger JE (1982) Tethered cord syndrome in adults. Neurosurg 57: 32-47.

7. Wilson DA, Prince JR (1989) John Caffey award. MR imaging determination of the location of the normal conus medullaris throughout childhood. AJR Am J Roentgenol 152: 1029-1032.

8. Saifuddin A, Burnett SJ, White J (1998) The variation of position of the conus medullaris in an adult population A magnetic resonance imaging study. Spine 23: 1452-1456.

9. Blout JP, Elton S (2001) Spinal Lipomas. Neurosurg Focus 10: e3.

10. Lew S, Kothbauer K (2007) Tethered cord syndrome: An updated review. Pediatr Neurosurg 43: 236248.

11. Warder DE (2001) Tethered cord syndrome and occult spinal dysraphism. Neurosurg Focus 10: e1.

12. Yamada S, Zinke DE, Sanders D (1981) Pathophysiology of 'tethered cord syndrome'. J Neurosurg 54: 494-503.

13. Yamada S (1996) Pathophysiology of the tethered spinal cord; in Yamada $S$ (eds): Tethered cord syndrome. Park Ridge American Association of Neurological Surgeons 29-48.

14. Stetler WR, Park P, Sullivan S (2010) Pathophysiology of adult tethered cord syndrome: Review of the literature. Neurosurg Focus 29: e2.

ISSN: 2574-1241

DOI: $10.26717 / B J S T R .2020 .26 .004423$

Ngo Minh Xuan. Biomed J Sci \& Tech Res

cC (i) This work is licensed under Creative

Submission Link: https://biomedres.us/submit-manuscript.php
15. Bui CJ, Tubbs RS, Oakes WJ (2007) Tethered cord syndrome in children: A review. Neurosurg Focus 23: e2.

16. Powell KR, Cherry JD, Hougen TJ, Blinderman EE, Dunn MC (1975) A prospective search for congenital dermal abnormalities axis. J Pediatr 87: 744-750.

17. Chapman P, Stieg P, Magge S, Barnes P, Mei F (1999) Spinal lipma controversy. Neurosurgery 44: 186-192.

18. Kucera J, Coley S, O’Hara S, Kosnik E, Coley B (2014) The simple sacral dimple: diagnostic yield of ultrasound in neonates. Pediatric Radiology 45: 211-216.

19. Henriques JG, Pianetti G, Henriques KS, Costa P, Gusmão S (2005) Minor skin lesions as markers of occult spinal dysraphisms-prospective study. Surg Neurol 63: S8-S12.

20. Chern JJ, Kirkman JL, Shannon CN, Tubbs RS, Stone JD (2012) Use of lumbar ultrasonography to detect occult spinal dysraphism. J Neurosurg Pediatr 9: 274-279.

21. Fone PD, Vapnek JM, Litwiller SE, Couillard DR, Mc Donald CM (1997) Urodynamic findings in the tethered spinal cord syndrome: Does surgical release improve bladder function? J Urol 157: 604-609.

22. Giddens JL, Radomski SB, Hirshberg ED, Hassouna M, Fehlings M (1999) Urodynamic findings in adults with tethered cord syndrome. J Urol 161: $1249-1254$.

23. Rajpal S, Iskander B (2011) Lipomyelomeningocele In: W Richard, Youmans Neurological Surgery. ( $6^{\text {th }}$ Edn.), PA Elsevier Inc, Philadelphia, USA.

24. Kesler H, Dias MS, Kalapos P (2007) Termination of the normal conus medullaris in children: A whole-spine magnetic resonance imaging study. Neurosurg Focus 23: e7.

25. Derek C Samples, Izabela Tarasiewicz (2016) Review and Classification of Occult Spinal Dysraphism and Tethered Cord Syndrome in Children. J Spine, an open access journal 5(4): 1000325.

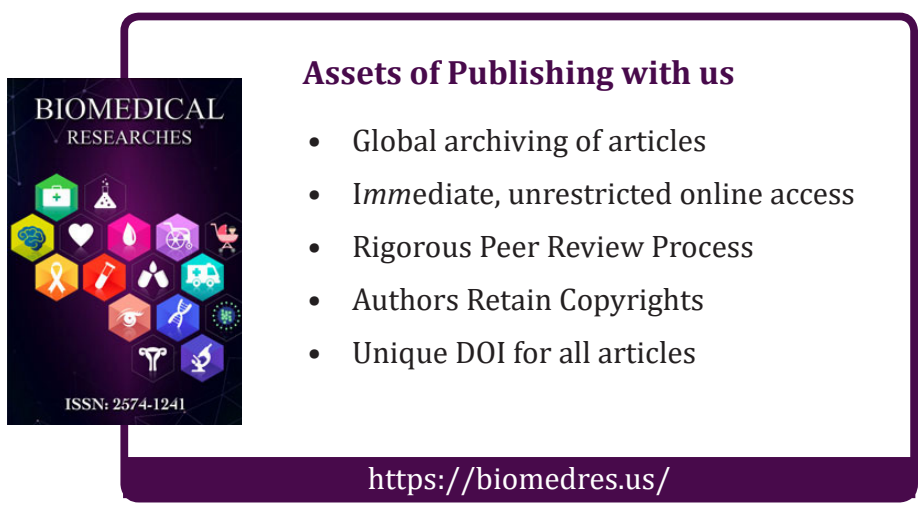

